\title{
البهاريون وحق التجنس في بنغلادش
}

\section{د. فرح ضياء مبارك}

قسم النظم السياسية/ جامعة بغداء مبارك

المقدمــة

ان الدذخل التاريخي المناسب للتعريف بـ (البهرة) الثيعة المسلمين في بنغلادش يبدأ من الباكستان

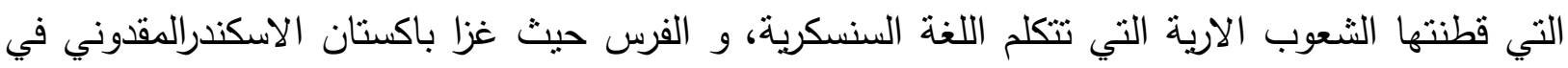
القرن السادس قبل الميلاد، واسرة موربا التي سيطرت على باكستان بقيادة الملك اسوكا الذي اعتنق البوذية،

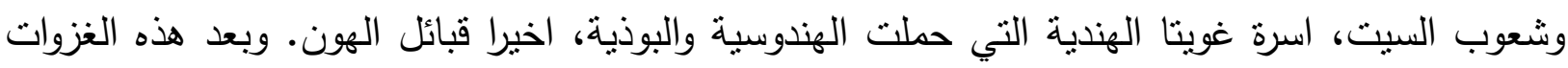

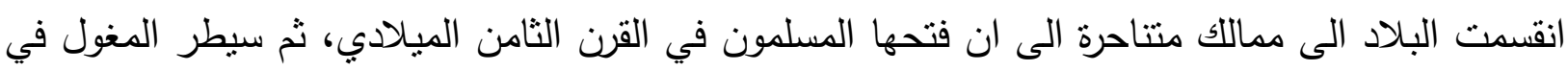

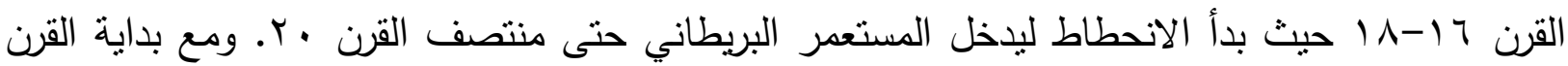
• r تطلع الهنود للاستقلال ولكن ظهرت فكرة تقسيم البلاد بين المسلمين والهندكية، فتحولت الفكرة الى حركة وبدأ تعرض المسلمين للظلم والاضطهاد مقابل احتكار الثروة والسلطة من جانب الهنود بدعم بريطاني في

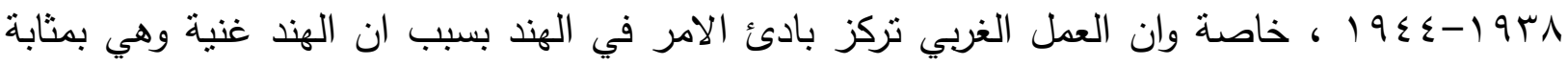

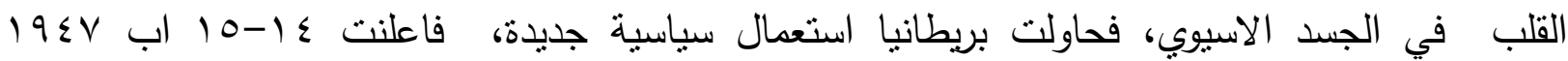

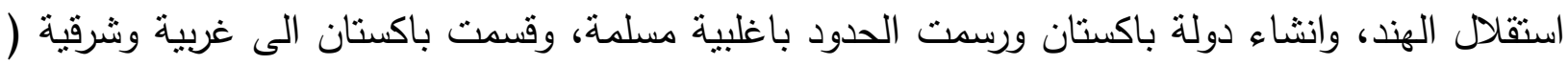

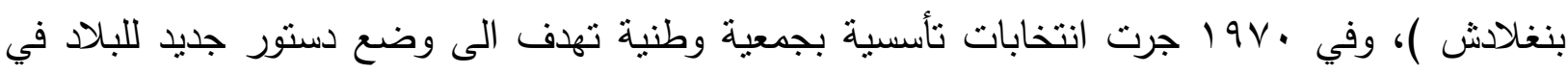

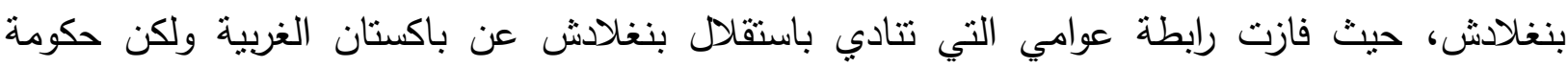

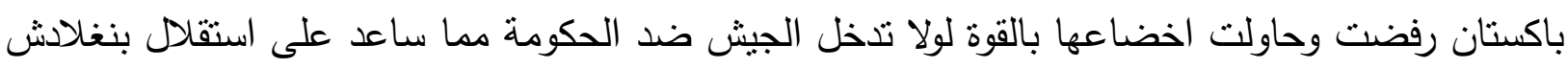

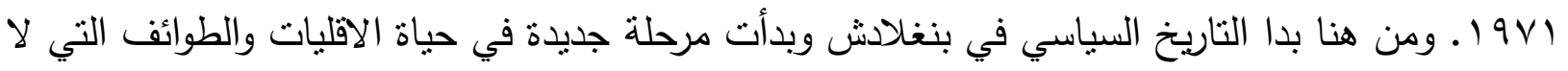

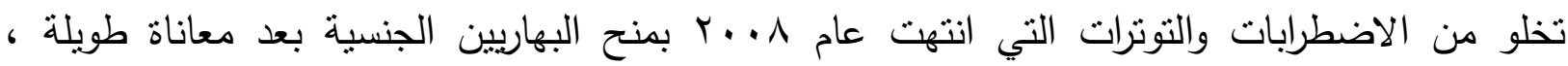

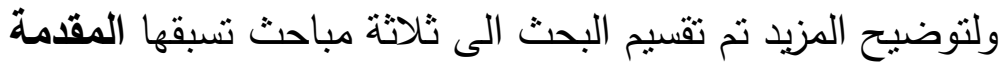

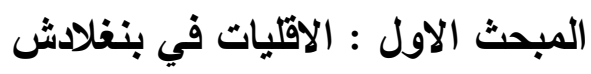

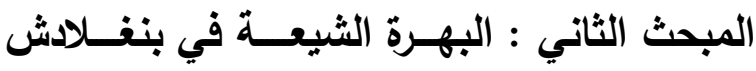

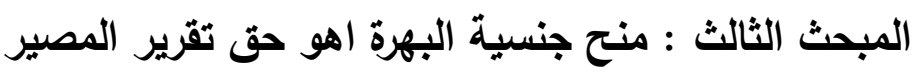
ام هو حق كسب الجنسية ام استراتيجية غربية ؟

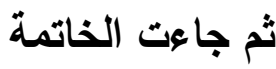
والتي اعقبتها المصادر المبحث الاول

الاقلبــات في بنغـلادش 
تقع جمهورية بنغلادش الثعبية جنوبي اسيا في الجزء الثمالي الثرقي لثبه القارة الهندية، وتعد اسيا الحالية هي بقايا امبراطوريات ونتائج لنزاعات ومن اهم دولها التي قامت على اساس ديني بعد انفصالها عن الهند 9 أ، هي باكستان التي انفصلت عنها بنغلادش (باكستان الثرقية) بعد حرب طاحنة عام ا الو ، ولحد الان مازالت الهند الام وباكستان الغربية والثرقية محط صدامات عنيفة دائمة بين قوميات وطوائف '.

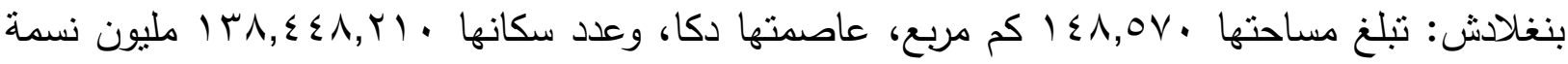
في بr...r ومعدل النمو السكاني r\%، وهي من افقر دول جنوب اسيا والاكثز كثافة سكانية والاقل نموا حيث يعيش بr\% من مواطنيها تحت خط الفقر اما متوسط دخل الفرد فيصل الى .. دولار شهريا. واهم المجموعات العرقية فيها هي :1^\% ينحدرون من الاربين ، والباقي مقسم بين الهنود والبنغال والبهار من المسلمين غير البنغاليين الذين هاجروا بعد تقسيم 9 ا I في الهند، وهم من اكبر المجموعات البشرية التي تاخذ شكل تجمعات عثائرية اصلها من باكستان وتقطن جنوبي شرقها ثم انتقلت الى شمال شرق بنغلادش. اما اهم اللغات في بنغلادش فهي اللغة الرسمية: البنغالية وهناك لغة يبانجلا وهي لغة هندية- ايرانية ولغة اوردو (لغة البهاربين) ولغة هندية - اوربية وهناك لغة سنسكرينية ولغة صينية -تبنية ولغة تسمى تنييتو بورمان ولغة تريبوراس والاخيرا والانكليزية التي تستعمل في التعليم العالي وفي الحكومة ‘ـ اما الاديان فيعد الاسلام الدين الرسمي حيث يشكل ^^^\% (شيعة وسنة) وهناك الهندوس والمسيحيون والروحانيون والجاليات

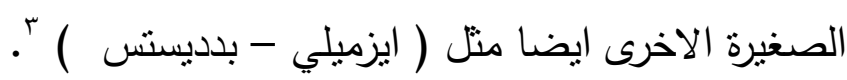
ان هذا البلد الاسلامي الذي استقل عام 9V1 (، بعد 10 عاماً من الحكم العسكري نراه اليوم منقسما على ذاته الى حزبين رئيسين يتتاوبان على الحكم هما: حزب رابطة عوامي بزعامة شيخة حسينة واجد، والحزب الوطني البنغلاديشي بزعامة خالدة ضياء، وهناك احزاب اخرى ذات ادوار ثنانوية مهششة، منل احزاب اشتراكية وحزب دور اعظم وحزب بنغلادش القومي ببرنامج يدعو لاقتصاد حر وحزب عوامي الذي بفضل السياسات المعتدلة والعلمانية وسياسات محدودة اشتراكية، وحزب جاتيا حزب رأسمالي وحزب ايزلامي جامات وحزب اسلامي يدعو لدور اعظم للاسلام في الحياة العامة. اما الحركات الاسلامية المتتددة في الداخل فقد قادت الى حرب داخلية غير معلنة بين هذه القوى وبين المؤمنين بالديمقراطية حيث يوجد في بنغلادش ( . . 70 ) مدرسة يسيطر عليها المنتسدون ويجندون الثباب فيها، وهذا ما قاد الى كثرة الاضرابات التي تتظمها احزاب المعارضة ولتكون النتيجة مواجهات بين الحكومة والمتظاهرين، ومن اهم الحركات الاسلامية الموجودة فيها هي :1- حركة الجهاد الاسلامي: (جوجايجد) تأسست عام 9 19 1 على يد مولانا عبد الرحمن فاروقي الذي قتل سنة 999 في افغانستان اثناء الحرب ضد الاحتلال السوفيتي، ومفتي عبد الحي، ويقدر عدد

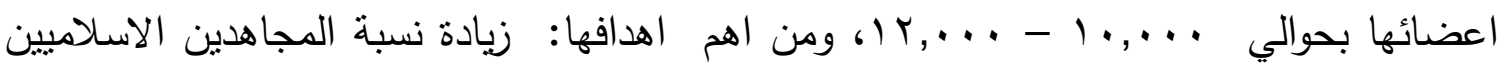
في العالم ولا يخفى ان الحركة تتلقى الدعم من الاستخبارات الباكستانية . 
ץ- جماعة المجاهدين: وهي جماعة متهمة بالارتباط مع القاعدة وتشرف على • ع مدرسة دينية وهي حركة معادية للتقافة الغربية وما يسفرعنها مثل دور السينما والمسارح، والمنظمات غير الحكومية ومن اهم قادتها اسد الله الغالب ودعمها من الدول العربية الخليجية بالتحديد ؛. r-شهادة الحكمة: وهي حركة مرتبطة مع القاعدة وقد اعلنت ذلك رسميا بعد القاء القبض على مؤسسها سيد كوثر حسين صديقي الذي تدرب على يد ابن لادن، وتتشط هذه الحركة وسط المدارس الدينية. ع- جاغراتا مسلم جاناتا بنغلادش: تأسست عام 1991 من قبل مولانا عبد الرحمن الذي يعرف بـ (ثاهي بهاي ) وتمويلها من عمليات ابتزاز الاغنياء في مناطق النفوذ ويتم استثمار الاموال في تجارة الاسماك والبرادات. كما لا ينكر ما لحركة طالبان في افغانستان من دور في انشاء تحالفات اسلامية داخلية ودفع الثباب للجهاد مع القاعدة ضد الاحتلال السوفيتي، مما دفحهم الى المطالبة

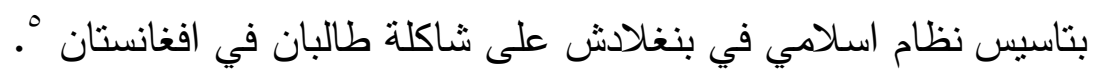
0- جمعية علماء اسلام: (تيار الديوبندي) تاسست عام هبو 19 لمواجهة الاحتلال البربطاني وللحفاظ

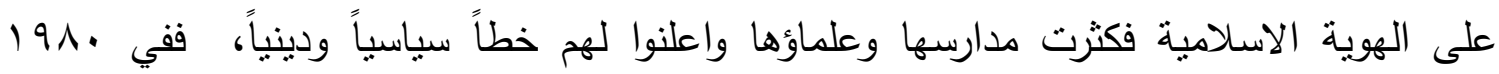

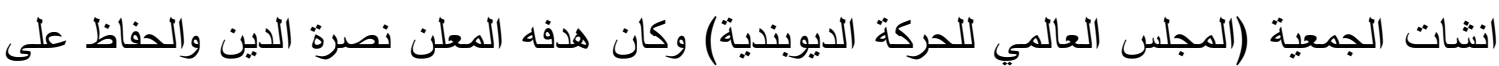
الهوية الاسلامية ، اما الهدف الحقيقي للمؤتمرات العثر التي عقدت كان توحيد الصفوف ووضع استراتيجية للتيار ومواجهة التيار السلفي والتيار الثيعي '. هذا يدل على ان معاملة الحركات لهذه المجموعات العرقية هي كاقليات، لذا لابد ان نوضتح معنى كلمة (اقليات) فهي مفهوم اخر لم يعرفه الاسلام، واستخدمه الاستعمار سلاحا للتذخل في شؤون الدول وتمزيقها " فرق تسد "، فالاستعمار استعمل اسلوب تدخل الامم المتحدة عند انتهاك حقوق الاقليات، وهذا قاد لاسلوب تأسيس احزاب للاقليات تسمى " اقلية الاحزاب القومية والوطنية " وبصنعون لهذه الاحزاب قادة عظام ساعدهم في ذللك التخلف، وقلة الوعي، فالاقليات مجموعة من الافراد يعيشون في بلد ما، او منطقة وينتمون الى اصل او دين او لغة او عادات خاصة وتوحدهم هوية قائمة على واحد او اكثر من هذه الخصائص، فالاقليات يحاولون الحفاظ على تقاليدهم والتمسك بعاداتهم والتأكد من تربية اولادهم على هذه التقاليد، واهم اسباب الفوارق بين الاقليات في المجتمعات هي : ا- المبدأ الراسمالي الذي حمل لواء الاقليات مع العلم ان فكرة المبدا الاصلية هي: العلمانية وهي فصل

الدين عن الدولة ، فلماذا تعامل الاقليات الدينية بتفرقة؟ . r- مبدأ النفعية ويقصد به تحقيق المصالح وافتراس المنافع لذا تتوقف معاملة الاقليات على المصالح

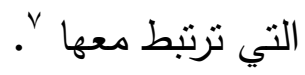
فاذا اعتبرنا العالم الاسلامي اقلية فأننا سنقدم معلومات عن هذه الاقلية في العالم: 


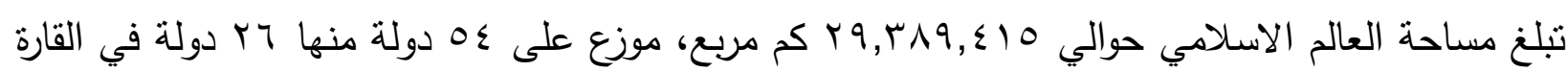

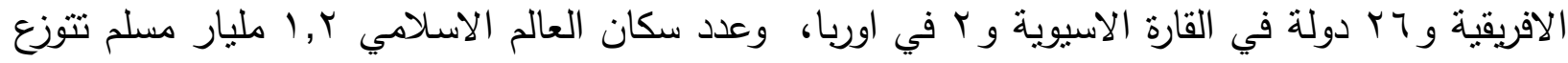
كالاتي :-

1- دول يثكل المسلمون فيها 9 \% \% وهي جميع الدول العربية، ما عدا السودان ولبنان، ودول اخرى هي افغانستان ، وتركيا، واندونسيا، وايران، وباكستان، وتنتاد، وغينيا، وجزر القمر ومالي.

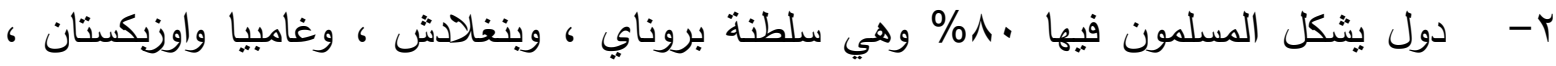
والنيجر، وتركمانستان، وطاجكستان، وارتيريا والسودان.

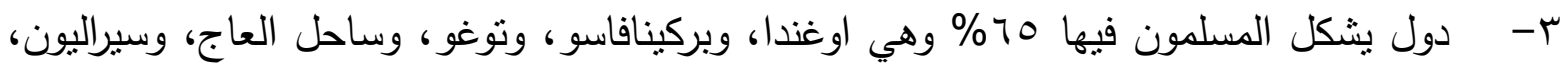
وغينا، وبيساو ، ونيجيريا، وماليزيا، والبانيا، واذربيجان وتتزانيا.

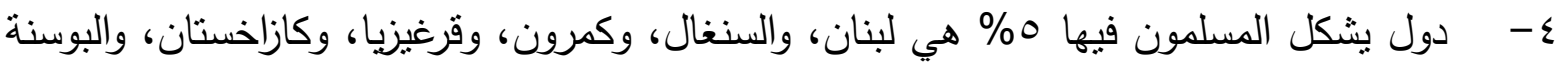

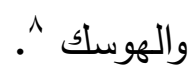

وهناك العديد من القوميات التي ينتمي اليها المسلمون وهي:

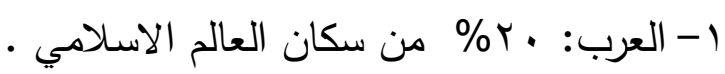

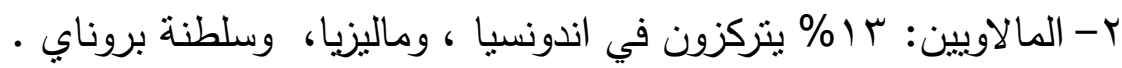

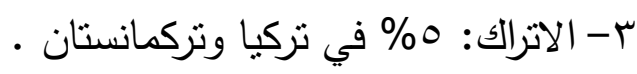

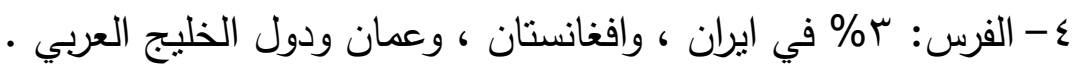

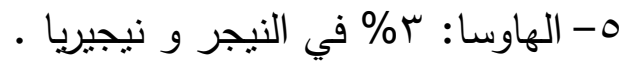
Y- الاوزبك: r\% ب افغانستان ، واوزبكستان ، وطاجكستان و قرنحيزيا .

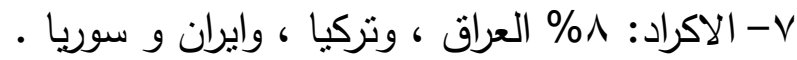

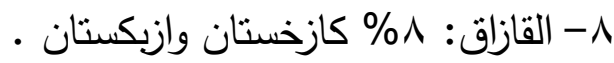

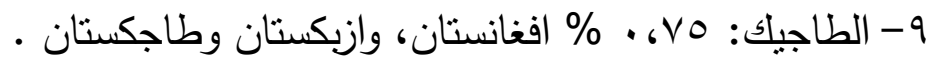
وهناك قوميات بنسب صغيرة هي ( البشتو - الاوردو - البلوش- الماندي- الايوا- بيوله- السنهاليون التتار - الفولاني - ماندنيتا- اليوروبا- البنغال - الطوارق - بالانتا - رالينوف- الاذريين - القرغيز - البيهار

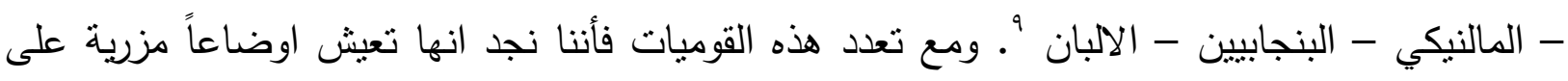

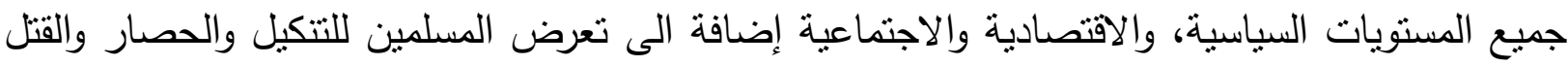

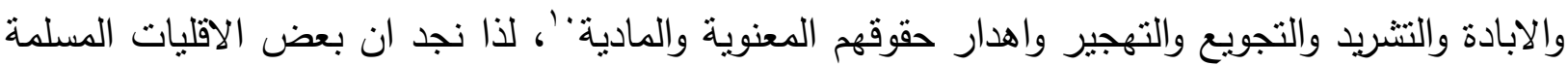
بدات تجد لها منفذاً اخر فمثلا نجد مسلمي شبه القارة الهندية اعتقدوا ان لابد لهم من دولة مسلمة يحكمونها على طراز اسلامي بعيدين عن الاكثرية الهندوسية بعد تقسيم الهند، واعلان دولة باكستان الغربية

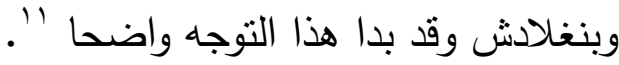


بدأ النزوح من الهند ومن بورما ايضا حيث نزح ( . . . . . 1 ) مسلم الى بنغلادش بسبب برنامج تصفية المسلمين تحت شعار (برنامج التخلض من الاجانب) حيث عُدَّ المسلمون اجانب دخلاء على الجسد البوذي ئ واستعملت بورما كل الوسائل البشعة بمساعدة خبراء يهود وجنود متخصصين لهذا الغرض واهم ما واجهه مسلمو بورما :- - هدم المساجد وتحويلها الى مراقص وحانات . - عدم السماح للاعاة بالتنقل ومنع المسلمين من الحج - مصادرة اوقاف المسلمين وتحويل مراقدهم الى دورات مياه او حظائر للخنازير والمواشي • - دخول الجيش البورمي الى المساجد بالاحذية والنجاسات حاملين زجاجات الخمر ب . وفضلاً عما تقدم فأن هناك مجموعات بشرية اخرى هم البوذيون الذين نزحوا من بورما بسبب التغيرات الديمغرافية حيث ان كل منطقة لابد ان يكون فيها منازل للبوذيين وتكون السلطة بايديهم يقطنون بيوت

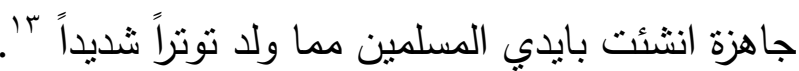
ولا يخفى ان ما عانته الاقلية الثيعية لايقل شأنا عما عانته الاقليات الدينية الاخرى في البلد الاسيوي التي

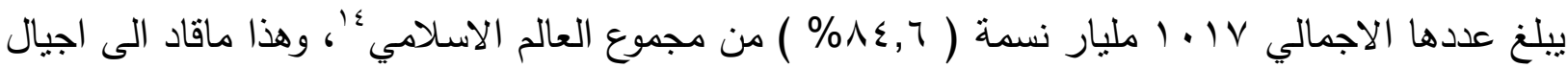
من التعصب، والتطرف الديني الذي لم ينه اضطهاد الجماعة الاحمدية (السنية) في بنغلادش على اعتبار انها جماعة تدعي انها مسلمة حيث جاءت بنظرة جديدة للنبي محمد (ص) تختلف عن باقي المسلمين، اذ ترى انه لم يكن خاتم انبياء التوحيد استنادا الى رأي مؤسسها وزعيمها (ميرزا غلام احمد) الذي ادعى انه المهدي المنتظر او المسيح الذي يظهر اخر الزمان حيث حاول المزج بين الصوفية والاسلام والارثذوكسية والهندوسية والمسيحية واعتبرها حركة احيائية ولم ير في حركته ديناً جديداً 10. ان هذه الاقليات المنشددة اتت بنوع خاص من حملات الترهيب ضد باقي الاقليات، واصبح التطرف الاسلامي يتسع في رقعته بشكل يثير القلق، وبشكل تهديدا خطيرا للتعايش السلمي في بنغلادش "، بخاصة ان في بنغلادش ما يقارب من · . . منظمة تبشيرية تتصيربة ايضاً تصل ميزانيتها لمليار دولار، ومهرتها

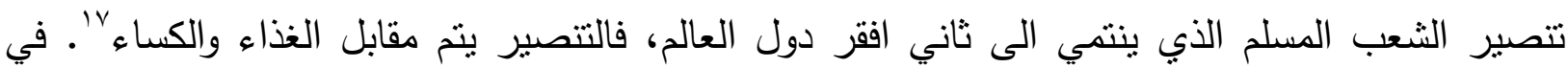
بنغلادش إضافة الى المسلمين والبوذيين والمسيحيين هناك الهندوس الذين يصل عددهم( . ., . , (1) ^1، ان هذا النزوح الهندوسي قاد الى اختلاف بين الهند وبنغلادش 19. ويبدو ان بنغلادش تحاول بدء مرحلة جديدة من الحوار بين الاديان حيث تم عقد مؤتمر بين المسيحيين

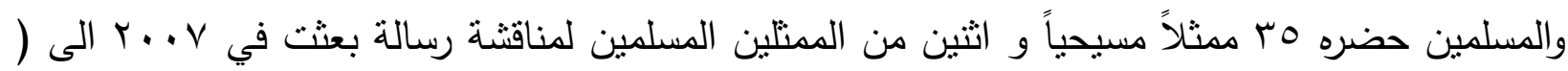
بندكتس السادس عشر والى القادة المسيحيين من قبل ^ر 1 عالماً مسلماً لمناقشة امور دينية، وهذا يدل على

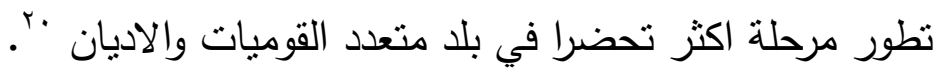
المبحث الثاني

البهـرة في بنغــلادش 
البهرة: كلمة هندية الاصل تعني (التجار) على اللغة الكجراتية، والبهرة او البوهرة مشتقة من (بوه راه) اي الطريق السوي او (بهو راه) الطرق الكثيرة، او (بهر) صفوف الابل او (بهراج) البصير بعواقب الامور، وبحتمل ان ترجع الكلمة الى اصول عربية : فالبهرة مأخوذة من كلمة (بهراء) وهي اسم قبيلة تسكن نواحي المدينة واليمامة وبعض العائلات في كجرات تدعي انها من الطائف والمدينة المنورة، قال ابن منظور (بهراء حي من اليمن)، والبهراء ذراع ممدودة، وبستعملها العرب للعمال الذين يرافقونهم في سفنهم، ثم شاعت الكلمة على كل من يصل من العرب للهند ومعناها الثائع هو التاجر ب، والبهر : ما اتسع من الارض، والبهرة:

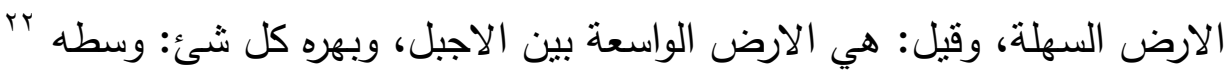
تاريخيا: وصل البهرة الى شبه القارة الهندية في ايام الخليفة المنصور العباسي عندما كان اقليم السند تحت سيطرة الخلافة العباسية بعد الخلافة الاموية عند دخول الاسلام اليه، فبعث الخليفة المنصور بـ (عمر بن حفص ) واليا على السند وهو على مذهب النتيع سرا، وقد تميز بحسن التدبير والحزم لذا نجده يرحب بالدعاة الثيعة حيث رحب بـ (عبد الله العلوي ) الذي جاءه هربا من المنصور وكان اول داعيه تطأ قدمه البلاد الهندية في منتصف القرن الثاني الهجري. وقد خاف عمر بن حفص على الداعيه الثنيعي فانزله عند امير هندوكي في الخفاء ومضت على هذا الحال عشر سنوات ولما علم المنصور بأمر عامله عمر بن حفص أمره بغزو بالاد هذا الامير ومطاردة الداعية الثيعي ، وما ان احس المنصور منه مماطله ارسل عمر بن حفص الى شمال افريقيا وبعث مكانه ( هشام بن عمر ) وفي عهده واجه الداعيه عبد الله العلوي وعدد من اتباعه مصرعهم وبعث هشام برأس الداعية الى الخليفة في بغداد بَّفي القرن الرابع الهجري بدأت تتوافد اعداد مختلفة من الثيعة قسم منهم القرامطة من البحرين وبلاد فارس فالتفوا حول دعاة اسماعيليين ، مما ولد اضطرابات قبلية عديدة بين العرب الموجودين انذاك ، اذ كانت القبائل تطالب بتقسيم البلاد الى : ثلاثثة اقسام :

$$
\text { - }
$$

فاستغل الداعيه الاسماعيلي (جلم بن شيبان الاسماعيلي) هذه الاوضاع وتمكن من الاسنيلاء على الحكم، فكانت اول حكومة لدولة اسماعيلية نتهدها القارة الهندية، اما القضاء على الدولة الاسماعيلية فقد جاء على يد من حكم بعده (حميد وابو الفتح داود القرمطي) الذي جاءت نهايته على يد (السلطان محمود بن السلطان سبكتكين الغزنوي)، الذي عمد الى القضاء على الحركات الضالة رغم ان القرمطي كان كثير المؤامرات والمعاهدات ودفع الاموال لصد السلطان محمود ولكن دون جدوى حيث تمكن السلطان محمود من اسره والقضاء على الدولة الاسماعيلية قضاءً تاماً وخرب عاصمتهم وضم الاقليم الى الدولة الغزنوية، وبهذا انتهت الدولة الاسماعيلية في البلاد الهندية وتوجهت فلول الطائفة الثيعية الى بلاد كجرات الساحلية الغربية وانضموا الى بني طائفتهم الذين وصلوا من اليمن ومصر وسموا (بالبهرة) او (البوهرة) ؛َ'. 
ان طرق دخول الثيعة البهرة الى شبه القارة الهندية للفترة من القرن 0 هـ - . اهـ كان كالاتي:-

\section{1- الاخول عن طريق اليمن ومصر:}

دخل عن هذا الطريق الاسماعيلية الفرع المستعلي وهم البهرة، فقد كان الدعاة يصلون من اليمن ومصر

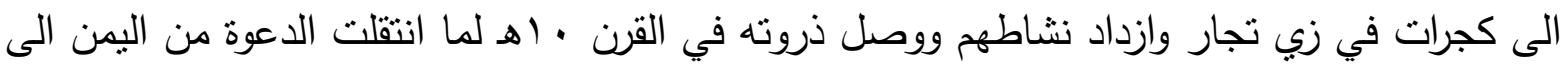

\section{r- الاخول عن طريق بلاد فارس :}

قدمت بقية الطوائف الثيعية الى البلاد الهندية، واخذت شكل طوائف وهي :-

- الاسماعيلية وفيها فرقتان: -

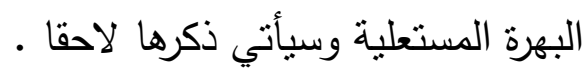

النزارية ( الاغاخانية )

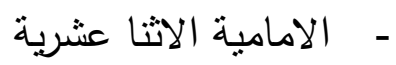

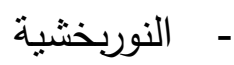

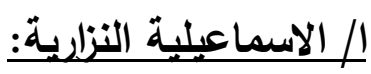

وهم الخوجات او الاغاخانيون حيث بدأ وصول الدعاة في منتصف القرن السابع الهجري ، ولما قام (هولاكو

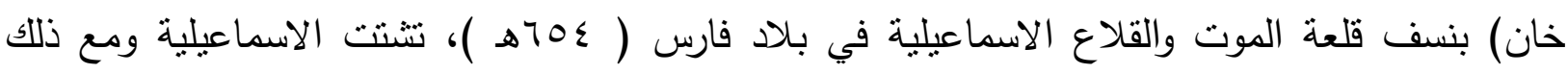
استمر وصول الاسماعيلية (الفرع النزارية) حتى القرن العاشر الهجري، وعلى الرغم من تولي الصفوبين حكم

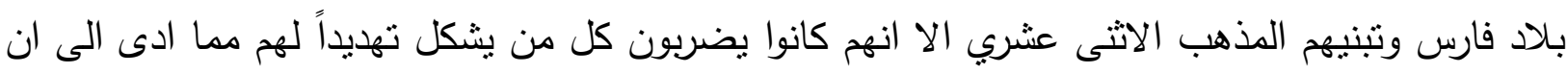
يعيش الاسماعيلون ظروفاً صعبة شجعهم على الانتقال الى البلاد الهندية.

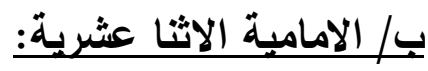
بدأ قدومهم في القرن الثامن الهجري حتى القرن العانشر الهجري عندما انهزم (همايون) ملك الهند على يد

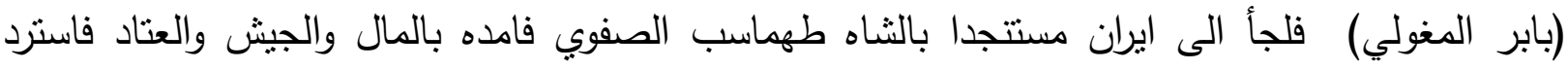

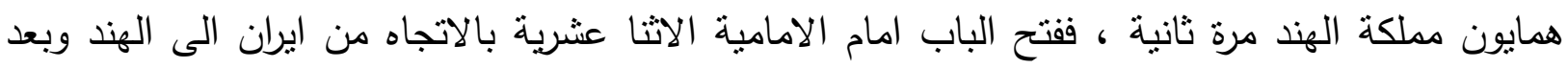

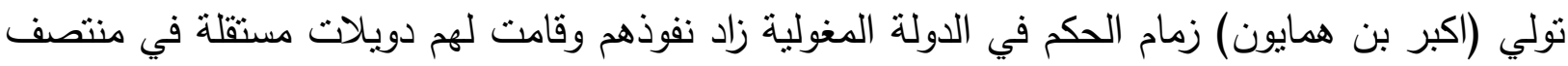
القرن العاشر الهجري في غرب البلاد الهندية وجنوبها.

ج/ النوربخثية: انتنرت في وادي كثمير والمناطق المجاورة على يد داعية قدم من خراسان الايرانية في نهاية القرن التاسع

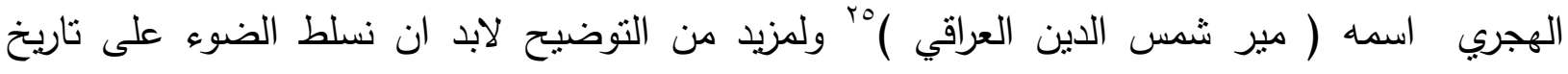

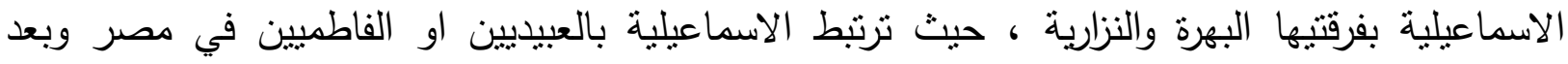

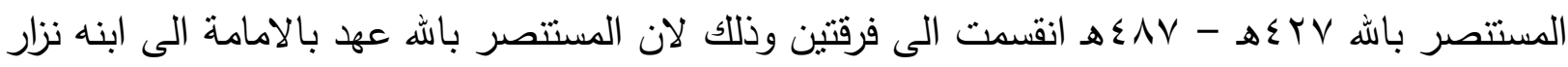

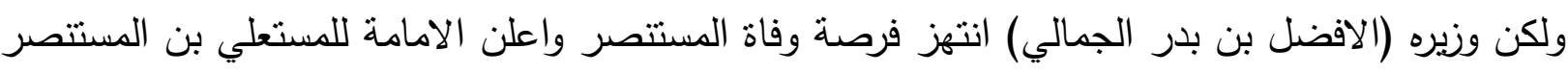


الاصغر وابن اخت الوزير الجمالي، وحارب الوزير نزار وقتله مع ابنه، ونجد ان اتباع المذهب الاسماعيلي رفضوا البيعة للمستعلي ونادوا بامامه نزار وابنائه وهكذا صار للاسماعيلية فرعان، وتتتمي بهرة الهند الى الفرع المستعلي ، والاغاخانية الى الفرع النزاري، واستمر حكم الاسماعيلية المستعليه لمصر الى ان استطاع

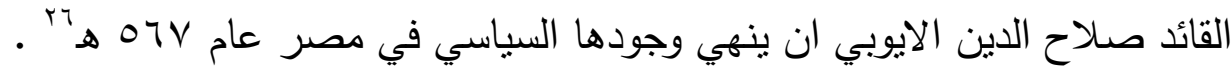
واكب ضعف الفاطميين في مصر ظهور فرع جديد للشيعة المستعليه في اليمن سمي الاسماعيلية الطيبية، واقاموا دولتهم التي عرفت بـ (الدولة الصليحية)على يد احد دعاتها (علي بن محمد الصليحي) استمرت ملتزمة بتعاليم الثيعة حتى وفاة الملكة (اروى بنت احمد) وبعد وفاتها اضمحلت الدولة وانقرضت عام بדهه، وظلت البهرة في الهند مرتبطة بالدعوة في اليمن حتى انتقلت تماما الى هناك Yr ، وللبهرة فرق عديدة هي :ا- الداودية: نسبة الى الداعية داود بن قطب شاه رابع الدعاه الذين استدعوا من اليمن لنقل الدعوة الى الهند، وقد تسلم الدعوة من الداعية داود بن عجب شاه وهو الذي اطاعه البهرة في الهند ولهذا سموا بالداودية وهم السواد الاعظم من هذه الطائفة ومركزهم مدينة سورت في اقليم كجرات ويوجد عدد كبير

$$
\begin{aligned}
& \text { منهم في }
\end{aligned}
$$

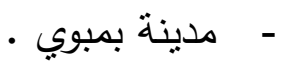

$$
\begin{aligned}
& \text { - وكرانتي الباكستانية. } \\
& \text { - مشرق افريقيا - } \\
& \text { - - وتتزانيا } \\
& \text { - } \\
& \text { - }
\end{aligned}
$$

ץ- السليمانية: نسبة الى سليمان بن بوسف بن اخ الداعية داود بن عجب شاه وكان سليمان عاملا على اليمن وبعد وفاة داود بن عجب شاه ادعى انه هو الداعية الذي بعده استتادا الى وثيقة مكتوبة لصالحه وليس لـ (داود بن قطب شاه)، ولكن لم يصدقه الا اهل اليمن ثم سافر الى الهند فرفضه البعض مما ادى الى تتاحر بين الداعيتين ولسليمان اتباع في:

$$
\text { - }
$$$$
\text { - - محراز في اليمن ويعرفون بالمكارمة. }
$$

ب- العلوية: نسبة الى علي بن ابراهيم بن الثيخ ادم صفي الدين وهي فرقة منشقة عن الداودية واصلها ان داود بن قطب شاه عهد الى ادم صفي الدين وهذا عهد الى عبد الطيب زكي الدين فخرج عليه حفيده علي بن ابراهيم بن الثيخ ادم صفي الدين فتبعه جماعه فاستقل وانشق عن الداودية. 
ع- نكوشيه: نسبة الى كلمة (نو) التي تعني (لا) وكوشت التي تعني (اللحم) اي: لا للحم وهذا من شعائرها عدم جواز اكل اللحوم، وهي فرقة منشقة من الداودية في اواخر القرن سا اه، حيث قالوا ان صلاحية شربعة محمد قد انتهت بانتهاء الف وثلاثمائة سنة. 0-ناكبورية: نسبة الى بلدة ناكبور المجاورة لمدينة بمبي، انشقت عن الداودية بسبب احد رؤوس الداودية من كجرات ويدعى (ملا عبد الحسين) الذي ادعى انه حجة من الامام المستور ولها اتباع

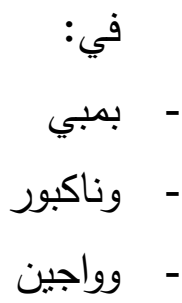

وهناك فرق اخرى صغيرة في البهرة منها فرقة هجومية وفرقة هبتية ^بـ. ولاستقراء توجهات البهرة نجد فيها شيئاً من الغيبيات حيث يؤمنون ان دعاتها يدخلون دور الستر عن العين كما حصل مع (ابو القاسم الطيب) باعتبار ان الداعية له ارتباط مع الامام المستور من منطلق ان الداعية هو الامر الناهي ومن ينترف بخدمته يتشرف بروئة الامام المستور، ومن ارائهم الاخرى اعتقادهم ان الاسلام احد طرفيه بيد الله والطرف الثاني بيد الداعية، ويؤمنون بالكتمان والتخفي انطلاقا من مبدأ ان الذهب يجب ان يخبأ. اما عن صحيفة الموتى فهي اثبه بصكوك الغفران التي اصدرتها الكنيسة في العصور الوسطى وفي هذه الصحيفة يكتب اسم المتوفي ومذهبه وائمته اضافة الى الدعاة وتوضع بيده، وبما انهم على المذهب الاثنا عشري فهم يحتفلون بيوم غدير (خم) فيصومون في 1 ا ذي الحجة ويغتسلون ويقدمون النذور والصدقات ربع منها للعامل وثلاثثة ارباعها للأعية، اما الصلوات الخمس فيصلونها في ثلاثة اوقات في مساجدهم التي يسمونها (جماعت خانه) وهي قبورهم والصلاة عبارة عن دعاء وترديده وعند ذكر اسم الداعية بسجدون له وادخل احد الدعاه قراءة الفاتحة والاخلاص بعد الصلاة فهم بعتقدون ان صلاتهم للامام والحج هو للامام وان الكعبة هي ردز الامام، وسلوكهم الاجتماعي ينم عن الالتزام والابتعاد عن المنكرات وعلى الرغم من ذلك فأن نساءهم متبرجات ولا يلتزمن بالحجاب الثرعي، ومع ذلك فأن في سلوكهم تاثز بالهندوس فهم يحتفلون معهم بمناسبة (ديوالي) احد اعياد الهندوس ويزينون مساكنهم ويعتبرونها بداية سنة مالية جديدة ويقفلون الدفاتر والحسابات القديمة ويفتحون دفاتر جديدة، نجد ثاثرهم بالهندوس من طريقة معاملتهم لموتاهم فهم ينثرون الزهور على قبر الميت ثم يقبلون وسط القبر ويعانقون اهل الميت بدون كلمة عزاء وَr، وهنا نجد الاختلاف واضحاً بينهم وبين الثيعة الامامية، وعلى العموم فان عدد الثيعة الاجمالي في العالم rا ب مليون نسمة“'، ويعد البهرة الثيعة اقلية في بنغلادش اذ لا يتجاوز عددهم ( . . . . نسمة وهم جماعة قليلة الامكانات ولا احد يهتم بمشاكلهم التي تتجسد في:- التيارات المعادية لهم المتمنلة في الدعوات المكثفة للفرقة الوهابية التي تتمتع بدعم واسع من قبل قوى متعددة في محاولة اسكات صوت هذه الاقلية والترويج لافكار باطلة ومنحرفة عنها. 
- الحرمان الثقافي وقلة الدعاة.

-

- ت تهور الاوضاع الاقتصادية والمعاناة من الفقر المدقع •

- تعرض شبابها للاغواء باستعمال الثروة لدفعهم باتجاهات منحرفة 'بـ

ان عدم وجود الديمقراطية وانعدام الحريات العامة ادى الى انتشار نزعة التسلط ورغبة الاستمرارية ودعم الولاءات العائلية للطوائف والاقليات المختلفة في مجتمع منتوع ومضطرب مثل بنغلادش • المبحث الثالث

\section{منح جنسية البهرة اهو حق تقرير المصبر

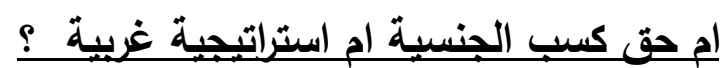

ان الاسلام دين ونظام قائم على العدل والثورى والمساواة بr، فلم يستخل الشعوب واعطاها حقها في تقرير مصبرها وحكم نفسها. اما حق تقرير المصير فظهر مصطلحاً في القرن العشرين ولم يعترف بهذا الحق الا بعد كفاح طويل فهو من الحقوق العامة للانسان التي لا تتصل بالفرد مباشرة وانما تمس النظام

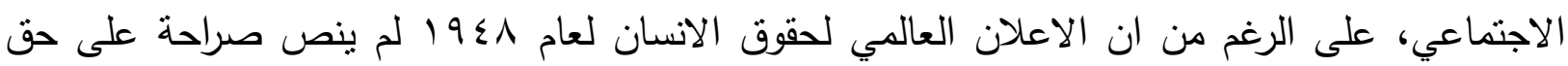
الشعوب في تقرير مصيرها خاصة وان الاعلان قد وضع في فترة السيطرة الاستعمارية التي لم تكن ترغب بتقييد نفسها به، وفي 1901 - . 197 تبنت الجمعية العامة للامم المتحدة قرارين بمنح الثعوب المستعدرة حق تقرير مصيرها من اجل انماء العلاقات الدولية بين الدول، كما اتخذت في عام • 19V قراراً بحق الثعوب المضطهدة في الحصول على تقرير مصيرها "َّاما العهذ الدولي الخاص بالحقوق المدنية والسياسية والعهد الدولي الخاص بالحقوق الاقتصادية والاجتماعية والتقافية لعام 9 أو فقد نص صراحة

على مبدا حق الثعوب بتقرير مصبرها، ولحق تقرير المصبر عدة معانٍ منها: - حق البلد في ان يختار بمله حريته دستوره ومركزه السياسي وان يتمتع بالسيادة على موارده وان يستقل باقامة علاقاته التجارية وان يصون قيمه الثقافية والاجتماعية بالاستقله باختيار نظام التعليم

فيه بشكل مستقل .

- حق الشعوب في ان تتصرف بحرية في ثرواتها ومواردها الطبيعية دون اي اخلال بالالنزامات الناشئة عن التعاون الاقتصادي الدولي القائم على المنفعة المشتركة . - - مق الثعوب في ان تتحرر وتحكم نفسها واختيار نظام الحكم الذي تراه مناسبا لها .

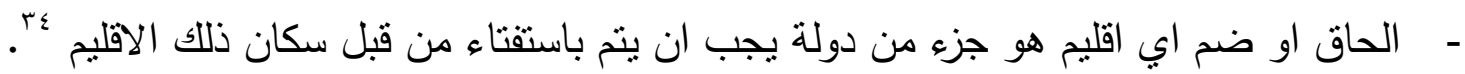
مادامت لكل امة سيادة متأصلة فيها باعتبارها متكونة من اتفاق الارادات المتقابلة لافرادها، فان هذا يعطيها الحق بتشكيل حكومتها الخاصة وفي انثاء دولتها المستقلة، هذا ما اكده ميثاق الامم المتحدة:" رغبة في تهيئة دواعي الاستقرار والرفاهية الضروريين لقيام علاقات سليمة ودية ومؤسسة على احترام المبدا الذي يقتضي بالتسوية في الحقوق بين الشعوب وبان يكون لكل منها حق تقرير مصبرها " . ب. 
وعليه ان فكرة الدولة المتعددة القوميات موجبة للقضاء على حالة اضطهاد الاقلية من قبل الاغلبية وعدم حرمان الثعوب من شخصيتها القومية، والحقيقة ان واقع المجتمع يؤكد على ان الاقلية دائما ترغب بالانفصال عندما تواجه اضطهاد الاغلبية ففي باكستان مثلا رأينا البنغاليين رفضوا العيش ضمن دولة واحدة مع البنجابيين الباكستانيين فانفصلوا الى دولة بنغلادش، وعلى الرغم من ان انفصالهم يؤكد انهم يملكون حق تقرير مصيرهم ولكن الواقع هو انفصال فردي دون اي سند قانوني. اما حق كسب الجنسية فهو من الحقوق الاجتماعية التي يتمتع بها الثخص ضمن النظام الاجتماعي للدولة، ويأتي هذا الحق من ان يكون لكل شخص مكان ثابت بتوطن فيه وبقيم اقامة دائمة، وبتمتع بكافة الحقوق التي يتمتع بها بقية المواطنين وان يحمل كل الوثائق القانونية التي تثبت انتماءه لهذا الوطن، وان ينتقل داخل دولته بحريه وينتقل الى دولة اخرى اذا ما تعرض لاضطهاد بسبب ما يحمله من افكار واراء، فلماذا يا ترى تاخر منح الجنسية للبهرة في بنغلادش الى ^ . . ب بعد ان اختاروا تقرير مصيرهم بالعيش والاستقرار في بنغلادش. على الرغم من ان الاعلان العالمي لحقوق الانسان 19 1 اوجب ضمان حماية حقوق الانسان بغض النظر عن جنسيته، الا ان لكل فرد حق التمتع بجنسية ولا يجوز حرمانه تعسفا او انكار حقه في تغييرها، والجنسية علاقة قانونية سياسية بين الفرد والدولة تترتب عليها اثار قانونية ومن هذه الاثار حماية الدولة للافراد الذين يحملون جنسيتها، وبالمقابل ترتب الجنسية على الفرد حقوقا والتزامات، فالفرد لكي يحمي مصالحه لابد ان يعتمد على صلة منتينة مع الدولة من اجل ان تؤمن له كل الحماية، والجنسية من اقدم الصلات هذه بّا. وعلى الرغم من عقد العديد من المعاهدات الدولية لمعالجة موضوع انعدام الجنسية وازدواج الجنسية، الا ان الدول ما زالت تنتدد في منح الجنسية للاشخاص الذين لايحملونها، وحاليا زادت المطالبات الدولية بأن يكون لكل فرد جنسية لمكافحة حالات انعدام الجنسية التي هي اسوأ الحالات حيث لايجد هؤلاء دولة تحمي حقوقه على الصعيد الدولي والداخلي، كما في حالة البهرة المسلمين في بنغلادش، و (البدون) في الكويت، اما عن الاسلام فهو يتخذ الدين معيارا للتمييز بين المقيمين في دار الاسلام حيث من كان من غير المسلمين فهو اجنبي، لان الاسلام دين وجنسية في ان واحد، وغير المسلم المقيم في دار الاسلام اما ان يكون ذميا او مستأمنا، فالذمي هو من يقيم اقامة دائمة او طويلة في دار الاسلام على ان يكون له ما للمسلمين وما عليهم وذلك بمقتضى عقد الذمة الذي بمقتضاه يكون الثخص من الرعايا المحكومين بالحكم الاسلامي، مقابل تكاليف مالية منرتبة على عقد الذمة، اما المستأمن فهو الحربي الذي ماي يقيم في دار الاسلام اقامة مؤقته بمقتضى عقد الامان الذي يستطيع ان يمنحه له كل مسلم ومركزه مركز الذمي ماعدا التكاليف المالية فهو غير ملزم بها واذا طالت مدة بقائه تحول الى ذمي وفي الحالتين لله وعليه ماعلى المسلمين وعليهم لّr. وبيدو ان البهرة كانوا مستأمنين لدى الدولة في بنغلادش لمدة طويلة الى ان تم منحهم الجنسية ليتحولوا الى مواطنين حاملين لجنسيات تثبت حقوقهم والتزاماتهم. ان الحديث عن البهرة يقودنا الى التركيز على الحرية الدينية التي تعد حجر الزاوية للايمقراطية وهو مقياس حيوي في نشكيل وصون نظام سياسي مستقر، حيث تستعمل الدول الغربية الديمقراطية وحقوق الانسان ومن 
ضمنها حق الحربة الدينية للتخخل في شوؤن الدول الداخلية ^^، والواقع ان الحرية الدينية التي تتادي بها الدول الغربية المفروض انها قيمة كونية والواقع انها مقيدة منتهكة ومنكرة حيث يعيش الملابين من الناس حول العالم في ظل انظمة تحاول اخضاع المعتقدات والممارسات الدينية للرقابة المتشددة، خاصة وان الدول لديها ممارسات وقوانين وسياسات تمييزية مجحفة بحق بعض الاديان واحيانا تهمل معاناة الاقليات الدينية او اتباع الاديان غير المعترف بها. ويبدو ان بعض هذه الدول موجهة من دول مستعمرة تحاول فرض اجنداتها ضد الاسلام في الدول التي تخضع لها، ويمكن الاطلاع على جزء مما يفكر به الغرب من اهداف عبر عنها صموئيل هنتجتون في كتابه (صراع الحضارات) حيث كتب يقول: " ان النزاع وفق خط الانقسام بين الحضارتين الغربية والاسلامية مستمر منذ . . I سنة فبعد صعود الاسلام، انتهى اكتساح العرب للغرب والثمال في تور عام (Yr) ومن القرن الحادي عشر الى القرن الثالث عشر، حاول الصليبيون بنجاح مؤقت الاتيان بالمسيحية والحكم المسيحي الى الاراضي المقدسة، ومن القرن الرابع عثر الى القرن السابع عشر قلب الاترالك العثمانيون الميزان، وفي القرن التاسع عشر واوائل القرن العثرين ومع انهيار القوة العثمانية، فرضت بربطانيا سيطرة الغرب على معظم شمال افريقيا والثرق الاوسط " 9جا وفي مقولة لبانديت نهرو ب791 حيث قال:" انفق البريطانيون في الهند وقتا طويلا لكبح جماح الطبقة المسلمة المثقفة واخضاعها والقضاء على نفوذها في جميع ميادين الحياة ووضعوا ناريخ الهند على قواعد اظهروا فيها الحكم الاسلامي هنالك منلبسا بالظلم والتعف وانهم كانوا المنقذين لبقية الطوائف والملل اذ حرروا الهند من

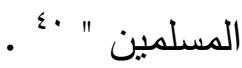

لقد بدأ في هذا العصر مهاجمة المعتقدات الدينية واستعمال الاغتيالات والطغيان التي ادت الى اضعاف الخلافات الايديولوجية التي هي مجموعة المعتقدات والافكار والاتجاهات التي تعمل للوصول الى نتيجة معينة في تحقيق الاهداف، كما ادت الى تدهور الوفاق الاجتماعي، فالربط بين الايديولوجية والطوبائية التي هي قيم وميول دينية وداخلية شجعت تحول القيم الدينية الى قيم عالمية تتبلور منطقيا لخلق انقسامات

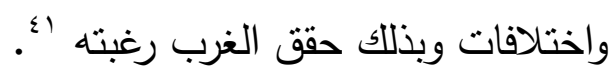
ان الغرب استعمل طرقاً ووسائل عديدة لضرب الاسلام والمسلمين في الهند وبنغلادش وغيرهما من الدول التي ارادوا ضرب الاسلام فيها وذلك عن طريق:- وضع نظم ادارية وسياسية ترمي الى انهيار مركز المسلمين التقافي والاقتصادي - محاولة اخفات صوت الثعوب المغلوبة على امرها باقامة انظمة اقتصادية وعدلية لاستخلالهم

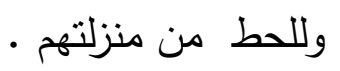
محاولة افسادهم اجتماعيا بترويج الفساد الاخلاقي، واشتاعة المبوقات وترويج المخدرات بين المسلمين، وتلويث ضمائر الناس ونفوسهم وعقولهم بوضع انظمة للتفرقة والتتابذ بينهم وغرس الاستكانه والاستسلام واقامة مدارس تعمل ستاراً للتناعب بعقول الشباب المسلم حتى لا تنقى فيهم ابي نزعة للتحرر، واستعمال الطوائف الاخرى والقاء اللوم عليها خاصة الطائفة التي يخثى من قوتها والعمل على 
اثارة الطوائف الاخرى عليها لاضعافها وزوال تقاليدها ولغتها وهذا ما حصل فعلا في بنغلادش ب؛. والنتيجة ان اسيا تعدّ موطنا لاعظم تجمع عالمي للقوميات والاقليات الطالعة والمنيقظة حديثا، التي يؤجج مشاعرها اي اضطهاد، او تقرقة تتعرض لها الطوائف هنالك مما جعل من اسيا مركزاً للاستقطاب السياسي، ان هذا لا ينفي العوامل التي ساعدت على ذلك المتمثلة في وسائل الاتصالات الجماهيرية، وخلق التمايز الاقتصادي بين الثروات خاصة وان بنغلادش مثنا من الدول الفقيرة وبالمقابل فأنها تعاني من زيادة سكانية، ومع ان الطرف الثرقي (اسيا) اصبح اليوم مركزاً حيوياً للنمو الاقتصادي والتاثير السياسي الصاعد، منذ ان بدأ التدخل الامريكي لضرب مصالح الاتحاد السوفيتي السابق من جهة، ومن جهة اخرى لخلق توازن في القارة يجعل الولايات المتحدة هي مرجع الحكم السياسي، ان سياسة هذه القوى العظمى بدأت بالتفاعل قبل حوالي خمسئة سنة، فاخذت الولايات المتحدة باستعمال التكنلوجيا والاتصالات والمعلومات والتجارة والارباح طرقاً لتحقيق الزعامة العالمية، بوسائل ديناميكية دولية تتبلور بالتأكيد على الديمقراطية السياسية والتطور الاقتصادي ووضع ايديولوجيات للايهام بتحقيق النجاح الفردي وتعزيز الحريات والربط بين المثالية والمصالح الذاتية لخلق مركب شديد الفاعلية، واخيرا اجتذاب الاشخاص النشطاء الفاعلين لتحقيق الفائدة المرجوه بّاء يقابل هذه الاستراتيجية الامريكية عداء من العالم الاسلامي وكلمة (العداء لامريكا) كما عرفه ديغبي اندرسون أنه:" رفض قوي او حتى كراهية للولايات المتحدة الامريكية وحكومتها وشعبها او طريقة حياتها"، حيث ان مصطلح العداء ظهر في القرن 1 ا واول من استخدمه محام فرنسي اسمه سيمون لينغويه في كتابه (حثالات اوربا) قال ان الحثالات سينون عالماً ومجتمعاً مخيفاً في امريكا وهو يقابل (الامركة) الذي استخدم عام ATV I في صحيفه فرنسية تحث على مقاطعة الاستيرادات الامريكية لانها ستقضي على الثقافة الفرنسية، هذا يدل على ان العداء لامريكا ليس في العالم الاسلامي وحده بل كان اصله في اوربا، خاصة وان العداء لامريكا في العالم الاسلامي خلقته امريكا لنفسها بسبب استعمالها سياسات واستراتيجيات لفرض العولمة - الامركة

ان منح الجنسية للبهرة المسلمين جاء متأخراً كما يبدو للوهلة الاولى وبعد دراسة الموضوع بكل ابعاده التاريخية والسياسية والاجتماعية والاقتصادية يتنين ان التأخير فيه الثئ الكثير من الاخفاق في حقوق الاقليات التي تعيش في بنغلادش، صاحبه اهمال النظام السياسي للتمييز المجتمي ضد الاقليات الدينية حيث سنت تشريعات لا نركز على الاضطهاد والتمبيز بقدر تركيزها على منع النزاعات والمضايقات، وعدم الزام الدولة برد الاعتداءات ضد الاقليات الدينية ، والثرطة لا تتدخل في فرض القانون وحماية الاقليات عندما تقع ضحية الجرائم، فهذه النشريعات تذور جميعها لمصلحة النظام السياسي وليس لمصلحة الاقليات. ان محاولة دولة بنغلادش خلق حالة تقارب وحوار يعمل ضمن الوحدة ومحاولة ادامتها بالتعدد، فالدولة هي اساس التقريب بين المختلفين واستقطاب الوحدة المتعددة ومنع التكفير والقتل، هذا التقارب هو حالة 
حضارية موجبه تقودها الدولة التي تعدّ الحاضن والحامي للشراكة. وحتى تحقق الدولة ونظامها السياسي دورها في حماية التقارب والتقريب لابد لها من وسائل اهمها: التأكيد على ان الدولة هي صاحبة المسوؤلية الاولى انطلاقا من مبدأ (كلكم راع وكلكم مسؤول عن رعيته)، وتوسيع مجالات الحربة في المجتمع بكل مؤسساته وتوجهاته، والعمل بجد على تخليص المجتمع من ضغط القبليات، وتضييق مساحات الاختناق بتوسيع مساحات الاشتراك، خلق حالة الامان الذاتي للجماعات، ورفع اسباب الخوف عنها، وبالمقابل توجيه الخطاب الديني ليكون في خدمة الهدف ووضع حد امام استشراء التطرف والتباعد، هذه الدولة التي نصبو ان تكون لتتجاوز حالة تمييز الاقليات واضطهادها وتأخير ابسط حقوقها في كسب جنسية الدولة التي تقطنها.

\section{هوامش البحث}

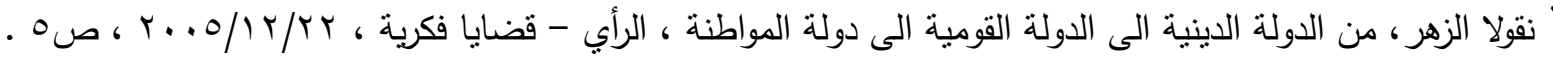
Microsoft $\&$ Encarta $(R$ Reference Library 2004

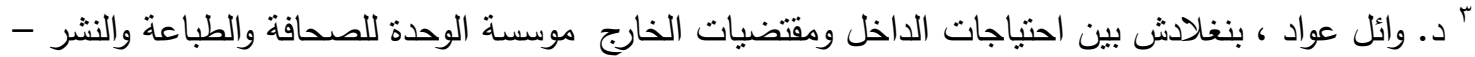
. $r .0 / 1 \cdot / r$

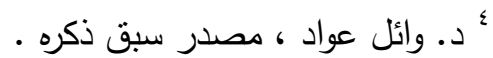

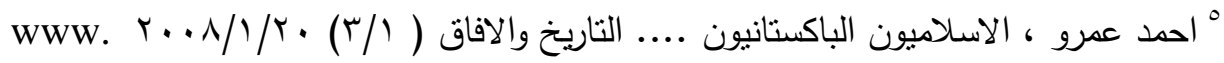
Ahmedamr2001@hotmail.com

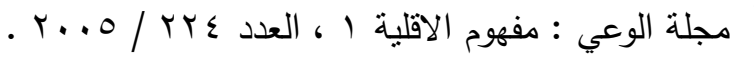

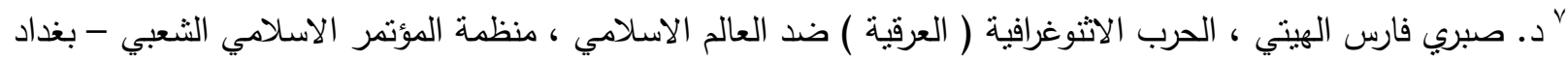
. 11-V ص 1990

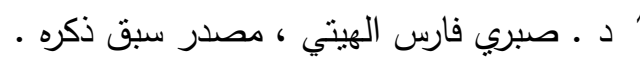

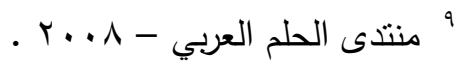

• اليران ما بعد الانتخابات ، لماذا يخاف العرب تلازم الاسلام والديمقراطية ؟ ولماذا يخشى الايرانيون طغيان الدولة الدينية ؟ .wWw.mainfatra.com $r \cdots / r / r \Lambda$ (1) منتدى الحلم العربي ، مصدر سبق ذكره .

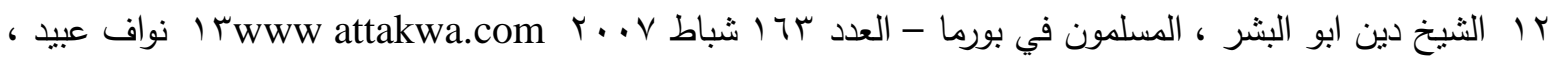

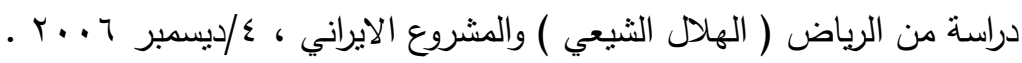

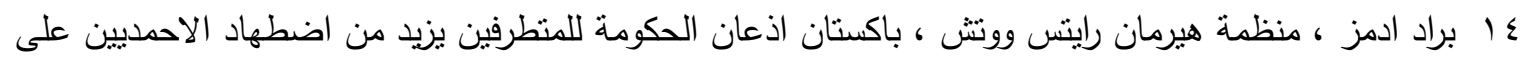

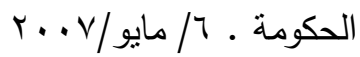

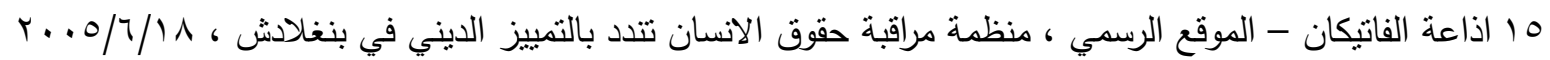

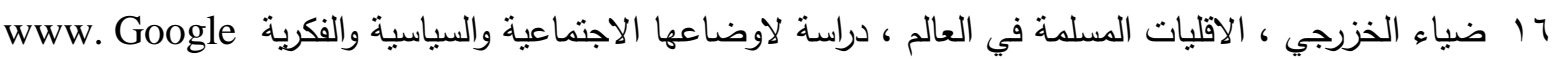
.com .

WWW.google.com ، امحمو د السيد : المسلمون في الهند V V

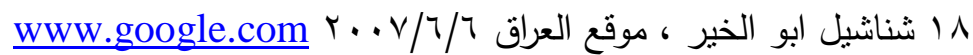




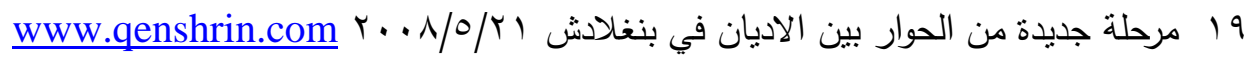

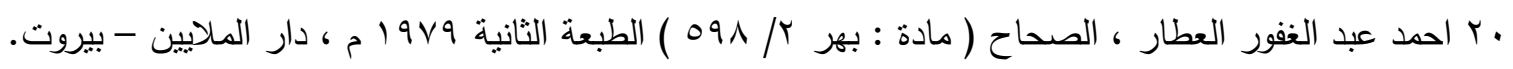

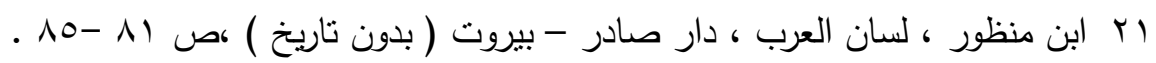

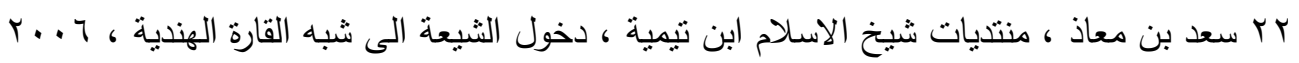

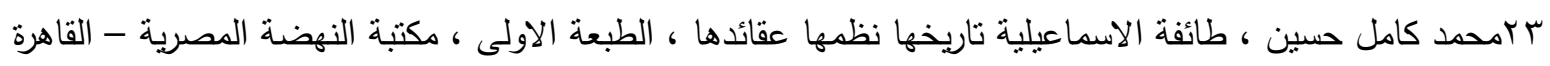

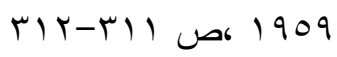
ع זسعد بن معاذ ، مصدر سبق ذكره .

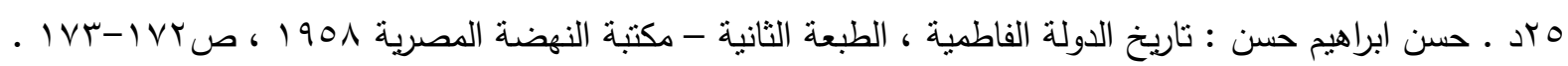

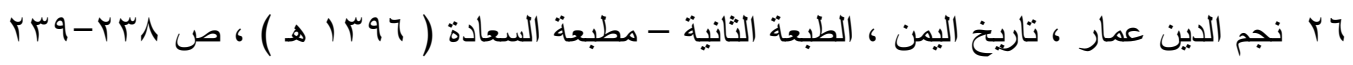

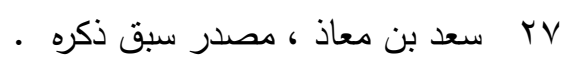

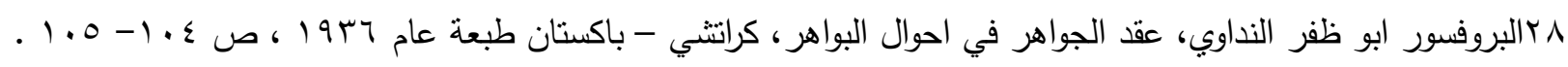

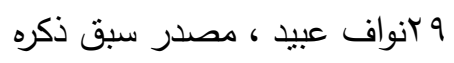
•r شبكة النبأ المعلوماتية ، تقرير الثبعة في بنغلادش يعانون الفقر والحرمان ، فهل من معين ؟ .

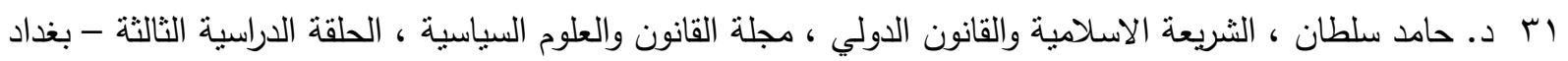
- VT 1979

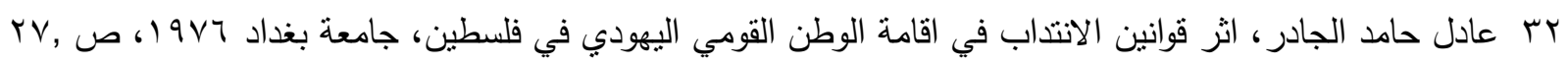

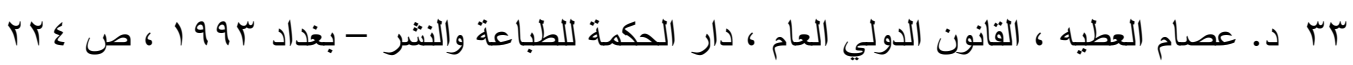

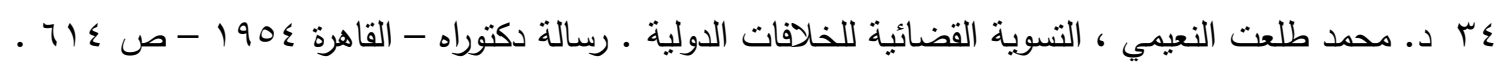
هب ولفغانغ فريدمان ، نطور القانون الدولي ، ترجمة لجنة من الاساتذة الجامعيين ، منشورات دار الافاق الجديدة - بيروت ، ص ص بس محمد كمال عبد العزيز، الثريعة الاسلامية والقانون الدولي ، مجلة القانون والعلوم السياسية ، الحلقة الدراسية الثالثة بغداد 1979 ص 99 ب .

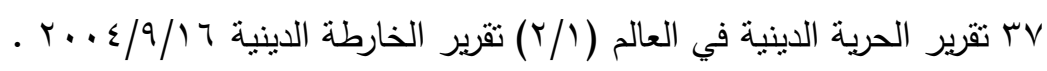

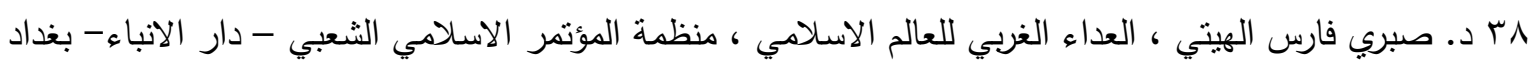

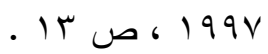

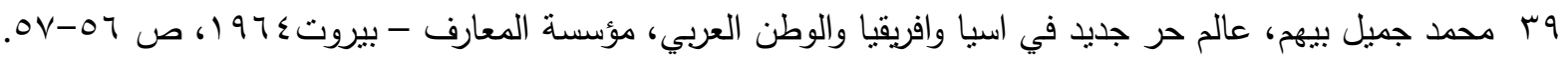

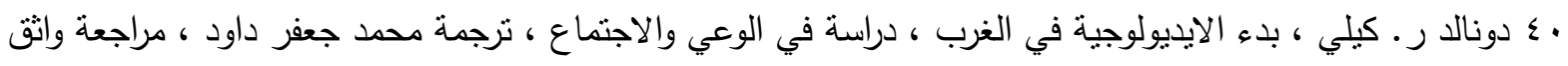

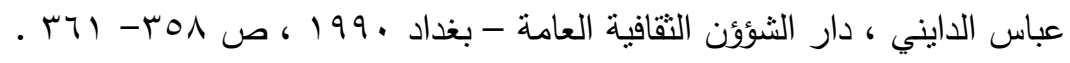

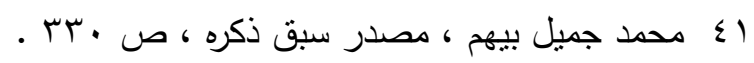

بـ زبغنيو بريجنسكي ، رقعة الثطرنج الكبرى ، الاولية الامريكية ومنطلباتها الجيوستراتيجية ، ترجمة امل الثرقي ، الاهلية

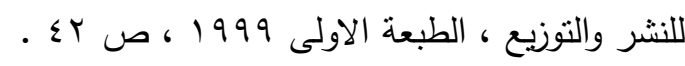

Sigrid Faath ( ed) . , Anti- Americanism in the Islamic World . ( London ; Hurst : princeton 43 , NJ : Markus Wiener Publishers, 2006 ) 305 p .

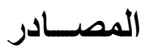

المصادرالعربية

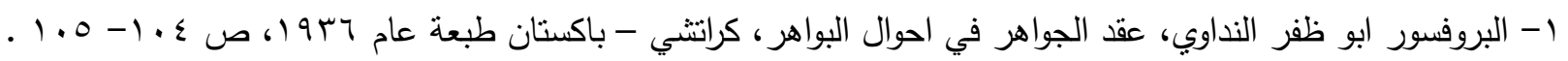




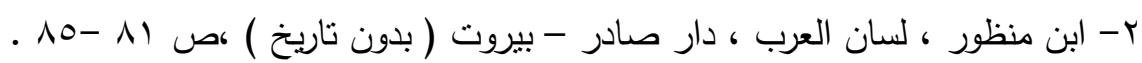

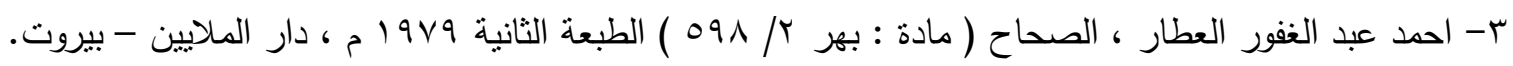

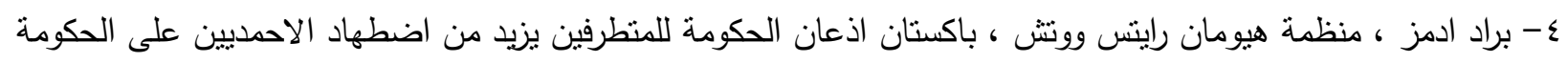

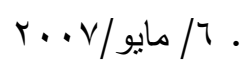

ه- دونالد ر. كيلي ، بدء الايديولوجية في الغرب ، دراسة في الوعي والاجتماع ، نرجمة محمد جعفر داود ، مراجعة واثق

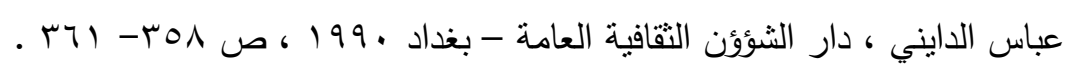

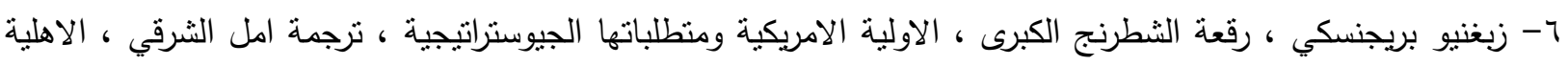

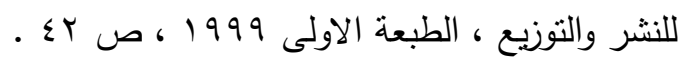

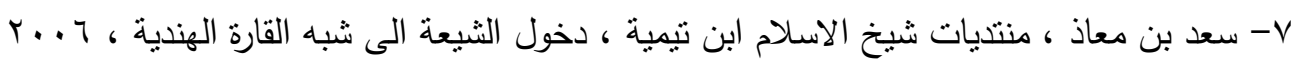

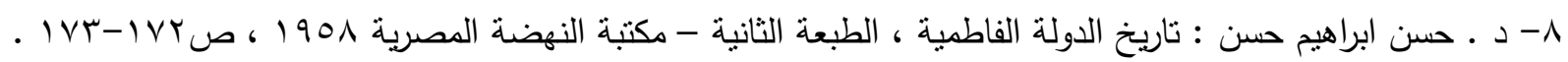

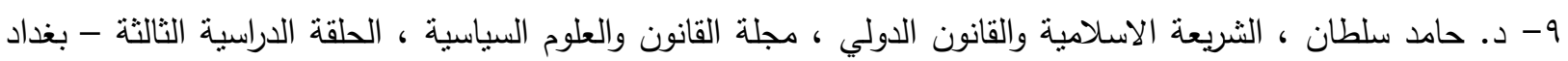
. VT 1979

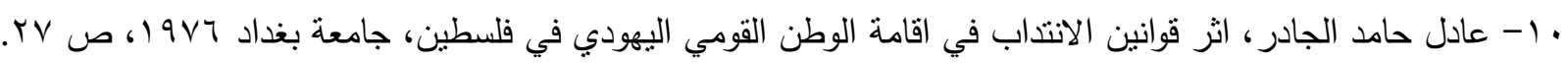

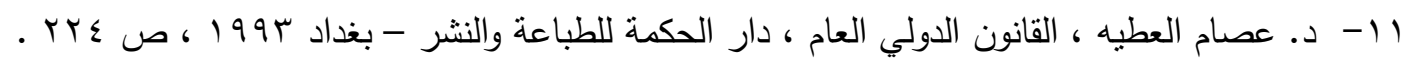

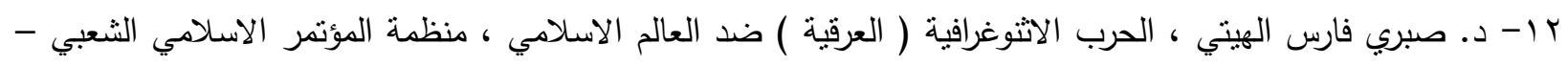

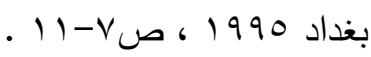

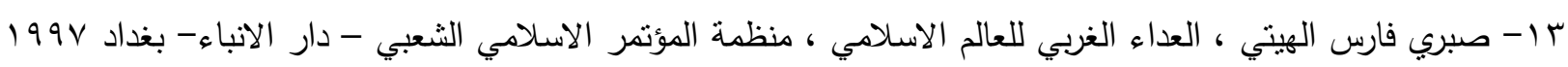
، ص سו.

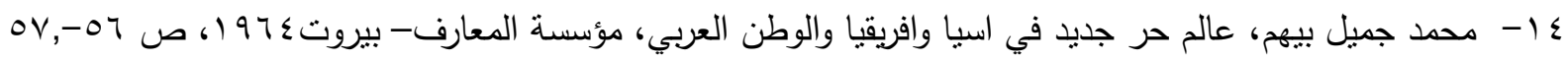
1 - محمد كمال عبد العزيز ، الثريعة الاسلامية والقانون الدولي ، مجلة القانون والعلوم السياسية ، الحلقة الدراسية الثالثة - بغداد 1979 ص 99 .

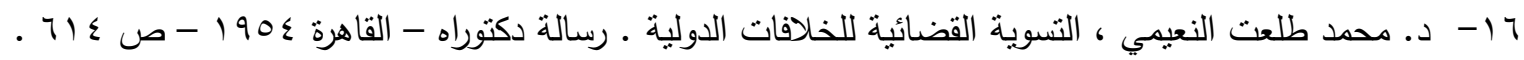

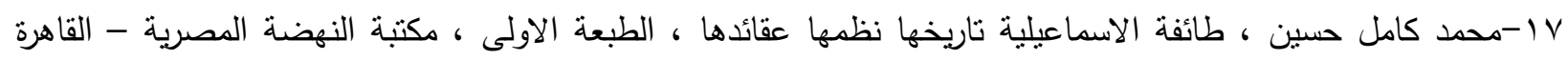
rIr-rII 1909

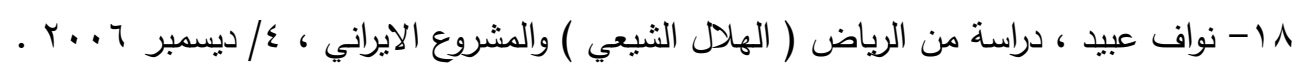

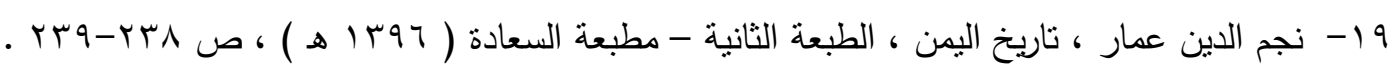

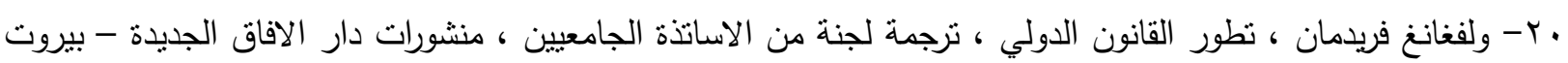

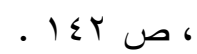

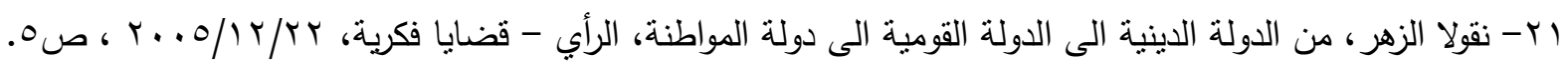

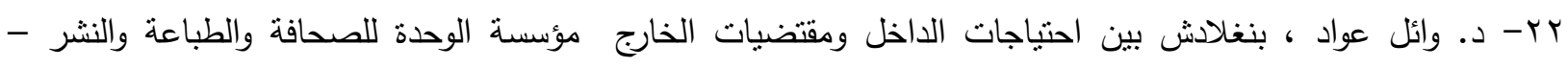
$r .0 / 1 \cdot r$

الصحف والمجلات

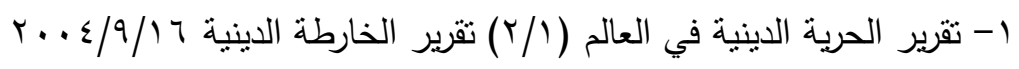

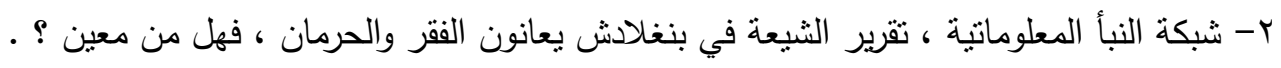


الانترنت

Ahmedamr2001@ hotmail.com

ץ- ايران ما بعد الانتخابات ، لماذا يخاف العرب تلازم الاسلام والديمقراطية ؟ ولماذا يخشى الايرانيون طغيان الدولة الدينية ؟ .www.mainfatra.com $r \cdots / r / r \Lambda$

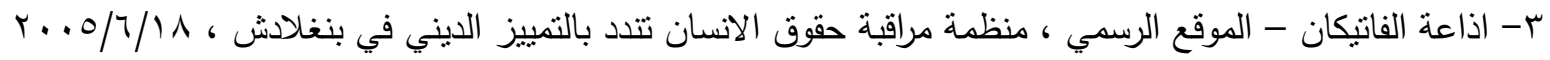

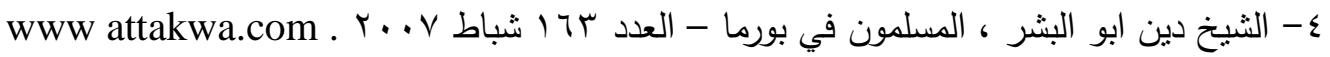

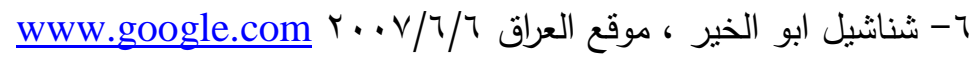
Www. Google .com ضياء الخزرجي، الاقليات المسلمة في العالم ، دراسة لاوضاعها الاجتماعية والسياسية والفكرية

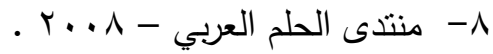

$$
\begin{aligned}
& \text { 9- محمو د السيد : المسلمون في الهند ، WWW.google.com }
\end{aligned}
$$

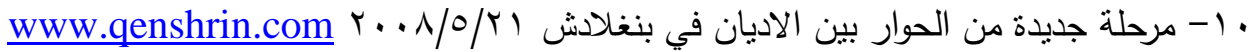

$$
\text { المصادر الاجنبية }
$$

Microsoft $($ Encarta $($ Reference Library 2004 - 1 Sigrid Faath (ed) . , Anti- Americanism in the Islamic World . ( London - 2

Hurst : princeton, NJ : Markus Wiener Publishers, 2006 ) 305 p .

\section{Abstract \\ Bouhra \& nationality Right in Bangladesh \\ Dr. Farah Dheia _ PhD. Political Sciences / Political System}

The Shiite Minority suffering from many Problems in Bangladesh, because the self- determinations having by Bouhra in Bangladesh was not enough \& They haven't good life circumstantions \& haven't all politics, social, economic \& religion rights. Then we not forget Bouhra coming from India, Pakistan, Yemen \& Egypt to Bangladesh after devoirs from Pakistan. The Bangladesh State Trying to builted \& related between all differences under democratic \& library . My Report contain Three parts :

Introduction

Part One : Minority in Bangladesh

Part Two : The Shiite Bouhra in Bangladesh

Part Three : Nationality Rights or Self- determination or

International Strategic

Conclusion

Reference

FARAH DHIAA ALSAFAR

PH.D.POLITICAL SCIENCES

Baghdad - Karadeet Mareem 222/33/house39 


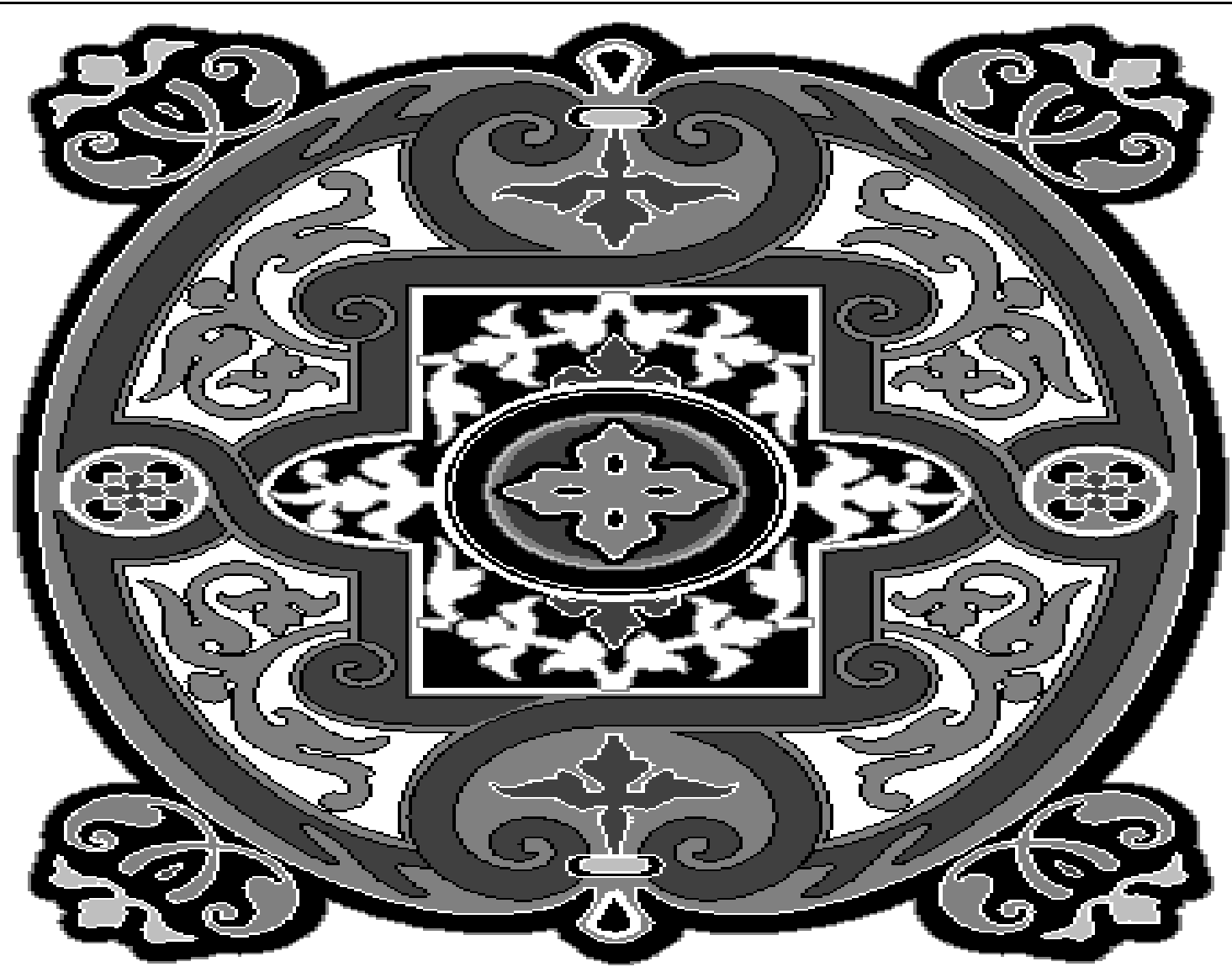


